Dokuz Eylül Üniversitesi-Mühendislik Fakültesi

Fen ve Mühendislik Dergisi

Cilt 19, Sayı 57, Eylül 2017
Dokuz Eylul University-Faculty of Engineering Journal of Science and Engineering Volume 19, Issue 57, September 2017

DOI: $10.21205 /$ deufmd.2017195790

\title{
Açık İşletmelerde Bantlı Konveyör Nakliye Sisteminin Değişen Kapasite ve Taşıma Mesafesine Bağlı Ekonomik Analizi
}

\author{
Tahir MALLI ${ }^{*}$, Alper GÖNEN ${ }^{1}$ \\ ${ }^{1}$ Dokuz Eylül Üniversitesi, Mühendislik Fakültesi, Maden Mühendisliği Bölümü, 35390, \\ İzmir \\ (Alınış / Received: 25.07.2017, Kabul / Accepted: 06.09.2017, \\ Online Yayınlanma / Published Online: 20.09.2017)
}

Anahtar Kelimeler Bantlı Konveyör, Açık İşletme, Nakliye Maliyeti

Özet: Dünyada yaşanan ekonomik büyümedeki yavaşlama madencilik sektörü de olumsuz etkilemektedir. Özellikle artan enerji maliyetleriyle birlikte teknik kriterler ve ekonomik koşulların sınırlandırdığı kısıtlar, işletmelerin rekabet gücünü zayıflatmaktadır. Maden işletmelerinde taşınması gereken cevherin nakliye maliyeti birim üretim maliyetinin büyük bir bölümünü oluşturmaktadır. Bu sebeple, nakliye sisteminde yapılacak iyileştirme ve geliştirme çalışmaları, zaman zaman işletme giderlerinin yarısına yaklaştığı görülen nakliye maliyetlerinin düşürülmesini gerekli kılmaktadır. Özellikle enerji giderlerinin düşürülmesi için yüksek verimlilik ve düşük emisyonlu konveyör teknolojisi ideal bir çözüm olarak önerilmektedir. Bantlı könveyörlerin, açık işletmelerde yükselen dekapaj miktarı, artan nakliye kapasitesi ve mesafelerinde önemli avantajlar sağladığı görülmektedir. Böylelikle, taşıma maliyetleri artan işletmelerin ancak bu şekilde birim üretim maliyetlerini rekabetçi düzeyde tutabilecekleri öngörülmektedir.

\section{Economic Analysis of Belt Conveyor System in Open Pit Mines Related to Changing Capacity and Transportation Distance}

\begin{tabular}{ll}
\hline Keywords & Abstract: The slowdown in economic growth in the world is also \\
Belt Conveyor, & affecting the mining sector. Particularly with increasing energy \\
Open pit, & costs, technical criteria and constraints imposed by economic \\
Transportation & conditions weaken the competitiveness of companies. The \\
Cost & transportation cost of the ore in mining constitutes a large part of \\
& unit production cost. For this reason, improvements to be carried \\
& out in the transportation system is required to reduce costs that \\
& covers half of operating expenses in some cases. Particularly low \\
& emission conveyor technology is proposed as a solution focused \\
& on reducing energy costs and increasing productivity. It is well \\
& known that, belt conveyors provide advantages in high \\
& overburden volume, high production capacity and increased \\
& transportation distances in open pit mines. Thus, it is predicted \\
& that companies can only keep unit costs at a cost-effective level.
\end{tabular}

*Sorumlu yazar: tahir.malli@deu.edu.tr 


\section{Giriş}

Dünya maden üretiminin \% 90'a varan önemli bir bölümü açlk işletme yöntemleri ile üretilmektedir. Yüzeye yakın maden yataklarının tüketilmesi ile birlikte açık işletme ekonomik derinliği her geçen gün artmakta ve kaldırılması gereken örtü kazı miktarlarıyla birlikte örtü-kazı oranları da $30 \mathrm{~m}^{3}$ /ton'a ulaşmaktadır. Bu nedenledir ki ekonomik üretim yapılabilmesi için dekapaj maliyetlerinin ve dolayısıyla birim üretim maliyetlerinin düşürülmesi gerekmektedir. Malzeme nakliyesi, açık işletme operasyonlarında büyük bir paya sahiptir. Birçok uzman nakliye giderinin işletme maliyetlerinin \%50'sine hatta bazı ișletmeler için bu rakamın \%60 değerine kadar arttığı görüşündedir [1].

Özellikle açık işletme kömür madenciliği, kömür talebindeki üst düzey artış nedeniyle önemli bir endüstri haline gelmiştir. Açık işletmelerde üretim payı yeraltı kömür madenciliğinden daha fazladır. Bu yüzden, üretim artışını ve açık işletme ekonomisini sağlamak ön plana çıkmaktadır [2].

Endüstrinin ihtiyacını karşılayabilmek için yüksek üretim kapasiteleri gerekmektedir. Üretilecek olan cevherin üzerindeki örtü kalınlığının, dolayısıyla kazılacak ve nakledilecek malzeme miktarının da fazla olması kazı, yükleme ve nakliye ekipmanlarının da büyük kapasitelere sahip olmalarını gerektirmektedir. Yüksek kapasiteli madencilik ekipmanları kullanarak, açık ocak birim maliyetleri düşmekte ve ekonomik açlk ocak derinliği daha da derinleşmektedir [3].

Açık işletme madenciliğinde makinaekipman seçimi işletme ekonomisini etkileyen, ocak tasarımı ve üretim planlamasında en önemli unsurlardandır. Tüm planlama prosesinin temel unsuru maliyet tahminidir ve gerçekte esas amaç belirlenmiş maliyet değerini en aza indiren seçimi yapmaktır [4].

Açık işletme madenciliğinde cevher ve dekapaj malzemesinin taşınması işlemi, açı işletme operasyonları içinde maliyetlere etkisi en fazla olduğundan ișletme ekonomisini belirleyici rolü olmaktadır. $\mathrm{Bu}$ nedenle işletmelerde uygulanacak nakliye yöntemi ve seçilecek makina-ekipmanlar, oluşması öngörülen giderleri belirlemede önemli olmaktadır.

Nakliyat işlemi en genel anlamıyla, kütlenin bir yerden bir başka yere tașınması ișlemidir. Madencilikte önemli bir yeri olan nakliyat, cevherin kazanıldığı üretim yerinden, cevher hazırlama tesisine, lavvar tesisine, atık sahasına veya tüketim yerine kadar ulaşmasını sağlayan tüm çalışmalar olarak tanımlanabilir. Madencilikte nakliyat yatay, eğik veya düşey düzlemde olabilmekte, çoğu zaman birkaç nakliyat yöntemi birlikte kullanılmaktadır [5].

İşletmelerde cevherin taşınması için farklı alternatif yöntemler bulunmaktadır. Nakliye yönteminin seçimine etki eden faktörler; rezerv, üretim kapasitesi, üretim yöntemi ve jeoteknik koşulları, cevher damarının yüzeyden derinliği ve eğimi, işletme ömrü vb'dir. Bunların içinde seçimi etkileyen en önemli parametreler; üretim kapasitesi ve işletme derinliğine bağlı olarak eğimdir. Bu yüzden, nakliye sisteminde yapılacak iyileştirme ve geliştirme çalışmaları, işletme ekonomisine önemli kazançlar sağlayacaktır [6].

$\mathrm{Bu}$ çalışmada, kamyon nakliyesi gibi konvansiyonel ve yaygın olarak kullanilmayan bant konveyör nakliyesinin ekonomik analizi yapılarak kapasite, taşıma mesafesi ve eğimlerine göre alternatif nakliye sistemi değerlendirilmektedir. 


\section{Bantlı Konveyör Nakliye Yöntemi}

Dünyada son ylllarda özellikle enerji verimliliğinin arttırılması, düşük emisyonlu teknolojilerin kullanılması ve maliyet azaltılması konusunda çeşitli çalışmalara odaklanılmıştır. Almanya'da toplam 450 taş ocağının nakliye sistemleri incelenmiş ve \%90'ında konvansiyonel olarak kamyon ile nakliye sisteminin kullanıldığı görülmüştür. Ancak yaplan inceleme ve değerlendirmeler sonucunda, \% 41'inde bantlı konveyörler ile nakliyatın daha ekonomik olarak uygulanabilir olduğu ortaya çıkmıştır [7].

Uygun nakliyat yönteminin seçilmesinde bazı faktörler göz önüne alınmaktadır. Bunlar; cevher nakliye kapasitesi, nakliyat mesafesi, nakliyat güzergahının eğimi, işletme topoğrafik koşulları, malzemenin fiziksel özellikleri, tane iriliği, kırılma şekli, nem oranı ve yoğunluğudur. Maden işletmelerinde uygulanan temel nakliye yöntemlerinin ana parametrelere göre karşılaştırması Tablo 1'de özetlenmektedir.

Tablo 1. İşletme kriterlerine göre genel nakliye yöntem seçimi

\begin{tabular}{|c|c|c|}
\hline Kriterler & Bant & Kamyon \\
\hline Kapasite(t/y) & $>2.000 .000$ & $<2.000 .000$ \\
\hline Malzeme & İnce parçalı & $\begin{array}{l}\text { iri parçall, } \\
\text { bloklu }\end{array}$ \\
\hline $\begin{array}{l}\text { Ekonomik } \\
\text { ömür }\end{array}$ & $\begin{array}{c}\text { Sinırlama } \\
\text { yok }\end{array}$ & $\begin{array}{c}10 \text { yıl } \\
\text { küçük-orta } \\
\text { olçcekte }\end{array}$ \\
\hline Mesafe $(\mathrm{km})$ & 16.0 & 8.0 \\
\hline Eğim & $-14^{\circ} /+18^{\circ}$ & $8^{\circ} / 12^{\circ}$ \\
\hline $\begin{array}{l}\text { İlkyatırım } \\
\text { değeri }\end{array}$ & Yüksek & Düşük \\
\hline $\begin{array}{l}\text { İşletme } \\
\text { gideri }\end{array}$ & Düşük & Yüksek \\
\hline Topoğrafya & $\begin{array}{l}\text { Esnek, eğim } \\
\text { azaltılabilir }\end{array}$ & $\begin{array}{l}\text { Engebeli } \\
\text { arazi }\end{array}$ \\
\hline
\end{tabular}

Sermaye ve ilk yatırım giderleri her iki nakliye alternatifi için uygulama ve saha verilerine bağlıdır. İşletme gideri konveyör sistem için daha düşüktür. Bant konveyör topoğrafik koşullara ve zemine uyum sağlayabilmektedir. Ayrıca kapasite olarak maksimum esneklik ve nakliye akışının sürekliliğine olanak sağlamaktadır $[8,9,10,11]$.

Konvansiyonel bant konveyor sistemleri, işletmelerde 18 derece eğim açısına (\%35) kadar çalışabilmektedir. Kamyonlar için bu eğim 8-12 derece gibidir[12]. Bant nakliyesi, kapasite olarak da uygun çözümler sağlayabilmektedir. Günümüzde 20.000 ton cevher $100 \mathrm{~km}$ mesafelere kamyon nakliyesine göre $\% 10$ değerinde taşınabilmektedir [13]. Bantlı konveyörler yukarıdan aşağıya doğru yapılan nakliyatta $-14^{\circ}$, aşağıdan yukarıya doğru yapılan nakliyatta ise $18^{\circ}$ eğime kadar sorunsuz olarak kullanılabilmektedir. Yüksek açılı bantlar kullanılarak nakliye eğimleri, $36^{\circ}$ 'ye kadar arttırılabilmektedir.

Genel olarak yüksek nakliye kapasitelerinde bant konveyör sistemi, eş kapasitedeki kamyon nakliyesine göre büyük ekonomik kazanımlar sağlamaktadır. Bant sistemi genellikle 20-30 km mesafelere kadar çalışmaktadır. En uzun bant sistemi 100 $\mathrm{km}$ mesafeye ulaşmıştır [11]. Sürekli nakliyat sistemlerinden olan bantlı konveyör büyük miktarlardaki yığın malzemelerin uzun mesafelere yatay ve eğimli nakledilmesinde uygulanmaktadır. Bantlı konveyörler, basit olarak iletilecek malzeme iki tambur arasına gerdirilmiş sonsuz bir bant üzerinde taşınmakta ve bu bant, bir veya birkaç tambur tarafından tahrik edilmektedir. Uzun iletim mesafelerinde ve büyük kapasitelerde oldukça ekonomik ve verimli bir nakliyata olanak sağladığından, günümüz madencilik ve nakliye uygulamalarında yaygın kullanım alanı bulmaktadır. 
Normal bantlı konveyörler $-20^{\circ} \mathrm{C}$ ile $+125^{\circ} \mathrm{C}$ sicaklığa dayanıklıyken, özel sentetik malzemelerden yapılan bantlar $+170^{\circ} \mathrm{C}$ sicaklığa kadar özelliklerini kaybetmeden iletim yapabilmektedir. Kullanilan yeni malzemeler sayesinde mukavemetleri arttırılan bantların buna bağlı olarak taşıma mesafeleri artmaktadır ya da birkaç konveyör seri olarak yerleştirilerek taşıma mesafeleri çok daha fazla arttırılabilmektedir. Pek çok küçük ve orta ölçekli madencilik operasyonlarında kamyon nakliyatı düşük yatırım maliyeti ile ekonomik açıdan en uygun yöntem olarak gözükmektedir. Buna karşın artan derinlik ve üretim kapasitesi, yüksek ilk yatırımına rağmen düșük ișletme maliyetiyle bant nakliyesini ön plana çlkarmaktadır [14].

Kamyon nakliyesi genel olarak üretime geçiş süresinin kısa tutulması istendiğinde, kısa ömürlü (10 seneye kadar) küçük ve orta büyüklükte üretim kapasitesine (2 milyon ton/yıl'dan küçük) sahip ocaklarda tercih edilir. Ayrıca, selektif üretim ve taşımanın söz konusu olduğu durumlarda, bant tesisinin olanaksız ve uygun olmadı ̆̆ cevher yataklanmasının kesikli yapı gösterdiği durumlarda kullanılır. Kamyon nakliyatı, bant taşımacılığının uygun veya ekonomik olmadığı derin ocaklarda, bant tesisinin sik sik yer değiştirmesiyle zaman kaybının çok olacağı kısa arınlı dik veya yatay uzanımlı kütlelerin hızlı şekilde üretiminde vazgeçilmez konumdadır [15].

Türkiye'de de açık maden işletmelerinde ve termik santral kömür besleme hatlarında bantlı könveyörlerin kullanımımı gelişmiş ülkelerde olduğu gibi yaygınlaşmaktadır. Çayırhan'da üretilen kömür, $3.7 \mathrm{~km}$ bant uzunluğundaki bant konveyör ile ocak ağzından lavvar ve santral tesisine taşınmaktadır (Şekil 1). Bant konveyörün kapasitesi 1200 ton/saat olup genişliği, $1000 \mathrm{~mm}$ ve hızı $4.7 \mathrm{~m} / \mathrm{sn}^{\prime}$ dir.

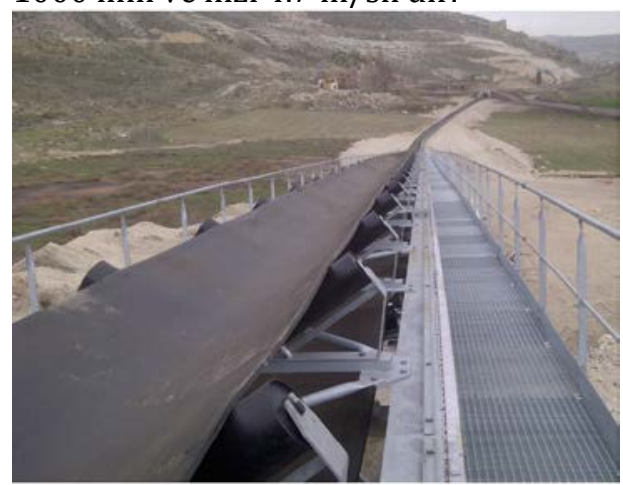

Şekil 1. Bant konveyör nakliye sistemi [16]

\section{Model Çalışma}

Nakliye yöntemlerinin ekonomik analizi ve seçimi için Visual Basic tabanlı bir bilgisayar yazılımı kullanılmıștır. Yazılım, farklı kapasite ve işletme değişkenleri için nakliye alternatiflerinin taşıma maliyetlerini hesaplamaktadır (Şekil 2).

Yazılım, bant konveyör sisteminde oluşacak birim taşıma maliyetini kabul edilen parametrelere göre hesaplamakta ve farklı senaryolar üretilmesine olanak sağlamaktadır.

Bantlı konveyör sistemleri için önemli parametrelerden olan cevher naklinin yapılacağı taşıma mesafesi, maksimum 10.000 metreye kadar arttırlarak değerlendirilmiştir. Bununla birlikte bir diğer önemli parametre olan kapasiteyi sağlayabilmek için bant hızları da arttırılarak değiștirilmiștir. Örneğin, bant hızı yıllık 1 milyon ton nakliye için 0,48 $\mathrm{m} / \mathrm{s}$, yıllık 10 milyon ton için ise 4,7 m/sn'ye kadar yükseltilmiștir. Ayrıca bir diğer faktör olan bant eğim açısı, farklı kapasiteler için yatay pozisyondan $6^{\circ}$, $12^{\circ}$ ve $18^{\circ}$ ye kadar yükseltmiştir.

$\mathrm{Bu}$ üç önemli faktörün değişiminde oluşması öngörülen maliyetler Tablo 2'de verilen diğer parametreler kabul edilerek incelenmiştir. 
T. Mallı ve A. Gonen / Açık İşletmelerde Bantlı Konveyör Nakliye Sisteminin Değișen Kapasite ve Taşıma Mesafesine Bağlı Ekonomik Analizi

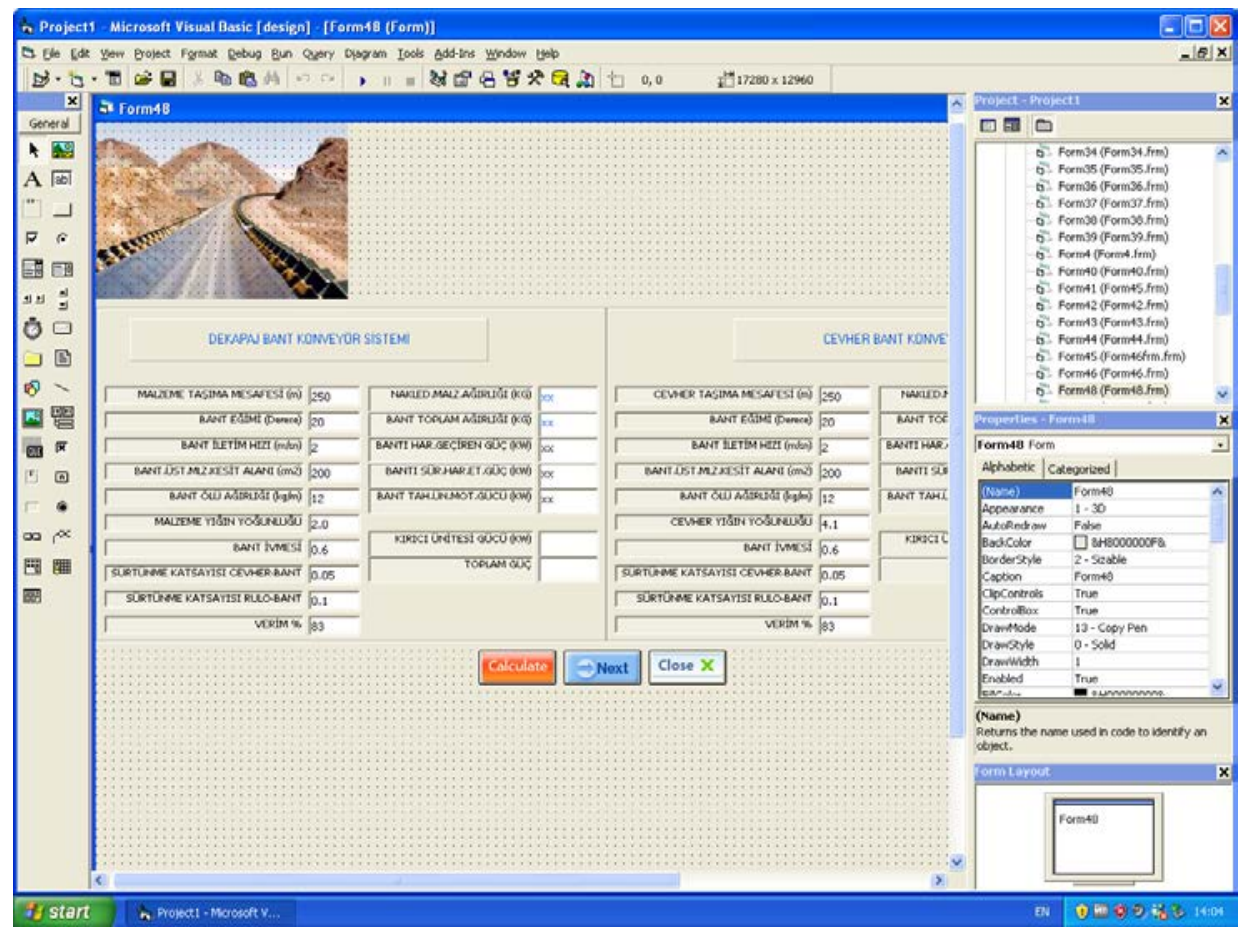

Şekil 2. Program arayüzü

Tablo 2. Bant nakliye sistemi parametreleri

\begin{tabular}{|c|c|}
\hline Parametreler & Değer \\
\hline $\begin{array}{l}\text { Nakliye yapılacak mesafe (m) } \\
\text { (min-max) }\end{array}$ & $\begin{array}{c}500- \\
10000\end{array}$ \\
\hline $\begin{array}{l}\text { Bant konveyörün hızı (m/s) } \\
\text { (min-max) }\end{array}$ & $\begin{array}{c}0,48- \\
4,7\end{array}$ \\
\hline Eğim açısı (derece) (min-max) & $0-18$ \\
\hline Bant konveyör genişliği (mm ) & 1000 \\
\hline $\begin{array}{l}\text { Bant konveyörün başlangıç ivmesi } \\
\left(\mathrm{m} / \mathrm{s}^{2}\right)\end{array}$ & 0,6 \\
\hline Rulo + bant ölü ağırlığı $(\mathrm{kg} / \mathrm{m})$ & 20 \\
\hline $\begin{array}{l}\text { Malzeme -bant arasındaki } \\
\text { sürtünme katsayısı }\end{array}$ & 0,05 \\
\hline $\begin{array}{l}\text { Rulo ile bant arasındaki sürtünme } \\
\text { katsayısı }\end{array}$ & 0,05 \\
\hline $\begin{array}{l}\text { Nakledilen malzeme yığın } \\
\text { yoğunluğu }\left(t / \mathrm{m}^{3}\right)\end{array}$ & 0,9 \\
\hline Teknik verim & 0,9 \\
\hline
\end{tabular}

\section{Değerlendirme}

Bant nakliyesinde etkili olan, işletme kapasitesi ve bant konveyör hattının eğimi göz önüne alınarak, bu üç önemli faktörün değișiminde olușması öngörülen tahrik motor güçleri ve maliyetler hesaplanmıştır

Nakliye hattı uzunluğu ve eğimi; tahrik motor gücünü arttırmaktadır. Örneğin 5 milyon ton nakliye kapasitesi için yatay pozisyonda ve 500 metre taşıma mesafesinde $68 \mathrm{~kW}$ motor gücü gerekirken maksimum eğim olan 18 dereceye çıkıldığında aynı mesafe için gerekli motor gücü $188 \mathrm{~kW}$, yani yaklaşık 3 katına çıkmaktadır (Tablo 3).

İşletmelerde artan kapasite mesafeyle birlikte doğrusal artarak, sistemin ilk yatırım tutarlarını yükseltmektedir. Nakliye hattı uzunluğu ve eğimi; tahrik motor gücünü arttırdığı için elektrik tüketimini ve elektrik giderini yükseltecek yönde etkilemektedir. 
T. Mallı ve A. Gonen / Açık İşletmelerde Bantlı Konveyör Nakliye Sisteminin Değișen Kapasite ve Taşıma Mesafesine Bağlı Ekonomik Analizi

Tablo 3. Bant konveyörlerin eğime bağlı tahrik motor güç değerleri (kW)

\begin{tabular}{|c|c|c|c|c|c|}
\hline & \multicolumn{5}{|c|}{ Nakliye mesafesi (m) } \\
\hline & 500 & 1000 & 2500 & 5000 & 10000 \\
\hline \multicolumn{6}{|c|}{ Q1=1.000.000 ton/yıl; v=0,48 m/sn } \\
\hline $\mathbf{0}^{\circ}$ & 14 & 27 & 68 & 137 & 273 \\
\hline $6^{0}$ & 22 & 44 & 110 & 218 & 437 \\
\hline $12^{\circ}$ & 30 & 60 & 150 & 299 & 597 \\
\hline $18^{\circ}$ & 38 & 76 & 188 & 377 & 754 \\
\hline \multicolumn{6}{|c|}{$\mathrm{Q} 2=2.500 .000$ ton $/ \mathrm{yll} ; \mathrm{v}=1,2 \mathrm{~m} / \mathrm{sn}$} \\
\hline $\mathbf{0}^{\circ}$ & 34 & 68 & 171 & 342 & 683 \\
\hline $6^{0}$ & 55 & 110 & 273 & 545 & 1092 \\
\hline $12^{\circ}$ & 75 & 149 & 373 & 747 & 1494 \\
\hline $18^{\circ}$ & 94 & 188 & 471 & 942 & 1884 \\
\hline \multicolumn{6}{|l|}{$\mathrm{Q} 3=5.000 .000$ ton $/ \mathrm{yll} ; \mathrm{v}=2,4 \mathrm{~m} / \mathrm{sn}$} \\
\hline 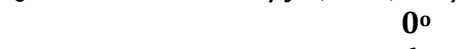 & 68 & 137 & 342 & 683 & 1366 \\
\hline $6^{0}$ & 109 & 218 & 546 & 1092 & 2184 \\
\hline $12^{\circ}$ & 149 & 298 & 747 & 1494 & 2988 \\
\hline $18^{\circ}$ & 188 & 377 & 942 & 1884 & 3768 \\
\hline \multicolumn{6}{|c|}{$\mathrm{Q} 4=10.000 .000$ ton $/ \mathrm{yll} ; \mathrm{v}=4,7 \mathrm{~m} / \mathrm{sn}$} \\
\hline $\mathbf{0}^{\circ}$ & 134 & 268 & 669 & 1338 & 2676 \\
\hline $6^{0}$ & 214 & 428 & 1069 & 2138 & 4276 \\
\hline 120 & 292 & 585 & 1462 & 2925 & 5850 \\
\hline 180 & 369 & 738 & 1845 & 3689 & 7378 \\
\hline
\end{tabular}

Tablo 4. Bant konveyörlerin eğime bağlı birim ton başına maliyet değerleri (TL/ton)

\begin{tabular}{|c|c|c|c|c|c|}
\hline & \multicolumn{5}{|c|}{ Nakliye mesafesi (m) } \\
\hline & 500 & 1000 & 2500 & 5000 & 10000 \\
\hline \multicolumn{6}{|c|}{$\mathrm{Q} 1=1.000 .000$ ton $/ \mathrm{yll} ; \mathrm{v}=0,48 \mathrm{~m} / \mathrm{sn}$} \\
\hline $\mathbf{0}^{\circ}$ & 0,59 & 1,12 & 2,73 & 5,4 & 10,75 \\
\hline $6^{0}$ & 0,61 & 1,17 & 2,84 & 5,63 & 11,21 \\
\hline $12^{\circ}$ & 0,64 & 1,22 & 2,98 & 5,9 & 11,75 \\
\hline $18^{\circ}$ & 0,67 & 1,28 & 3,13 & 6,21 & 12,37 \\
\hline \multicolumn{6}{|c|}{$\mathrm{Q} 2=2.500 .000$ ton $/ \mathrm{yll} ; \mathrm{v}=1,2 \mathrm{~m} / \mathrm{sn}$} \\
\hline 0o & 0,26 & 0,49 & 1,20 & 2,37 & 4,72 \\
\hline $6^{0}$ & 0,28 & 0,53 & 1,31 & 2,59 & 5,16 \\
\hline $12^{\circ}$ & 0,3 & 0,58 & 1,42 & 2,82 & 5,62 \\
\hline $18^{\circ}$ & 0,33 & 0,63 & 1,54 & 3,07 & 6,11 \\
\hline \multicolumn{6}{|c|}{$\mathrm{Q} 3=5.000 .000$ ton $/ \mathrm{yll} ; \mathrm{v}=2,4 \mathrm{~m} / \mathrm{sn}$} \\
\hline 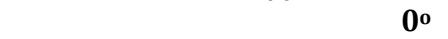 & 0,15 & 0,28 & 0,69 & 1,36 & 2,71 \\
\hline $6^{0}$ & 0,17 & 0,32 & 0,79 & 1,58 & 3,16 \\
\hline $12^{\circ}$ & 0,19 & 0,37 & 0,90 & 1,79 & 3,58 \\
\hline $18^{\circ}$ & 0,21 & 0,41 & 1,01 & 2,02 & 4,04 \\
\hline \multicolumn{6}{|c|}{$\mathrm{Q} 4=10.000 .000$ ton $/ \mathrm{yll} ; \mathrm{v}=4,7 \mathrm{~m} / \mathrm{sn}$} \\
\hline $\mathbf{0}^{\circ}$ & 0,09 & 0,18 & 0,44 & 0,87 & 1,73 \\
\hline $6^{0}$ & 0,11 & 0,22 & 0,54 & 1,08 & 2,15 \\
\hline $12^{\circ}$ & 0,13 & 0,26 & 0,65 & 1,29 & 2,58 \\
\hline $18^{\circ}$ & 0,16 & 0,31 & 0,75 & 1,50 & 3,00 \\
\hline
\end{tabular}

Yatırım ve operasyon giderleriyle birlikte artan toplam sistem maliyeti, birim ton başına taşıma maliyetlerini de oldukça arttırmaktadır (Tablo 4).

Yatay eğimli ve kısa mesafeli hatlarda (500 metre); kapasite 10 katına çıktığında birim taşıma maliyet değeri yaklaşık 6'da birine düşmektedir. Aynı mesafeler için eğim 18 dereceye yükseldiğinde ise maliyetler yaklaşık 4'te birine düşmektedir. 
$\mathrm{Bu}$ nedenle olabildiğince bant hattını düşük eğimlerde tasarlamak gerekmektedir. Ancak bunun mümkün olmadığı koşullarda ve eğim açısının düşürülemediği durumlarda ise bant hızını arttırıp kapasiteyi yükselterek daha ekonomik taşıma alternatifleri oluşturulabilir.

Taşıma alternatiflerinde, en düşük birim taşıma maliyeti, yatay (0 derece) eğimli konveyör hatlarında oluşmaktadır (Tablo 5). Eğimle birlikte bu maliyetler tahrik motor güçlerine bağlı olarak elektrik giderini arttırdığından genel giderlerin yükselmesine neden olmaktadır.

Tablo 5. 0 derece eğimli bant nakliye sisteminde taşıma maliyetleri (TL/ton)

\begin{tabular}{cccccc}
\hline $\begin{array}{c}\text { Kapasite } \\
\text { ton/yl }\end{array}$ & \multicolumn{5}{c}{ Taşıma mesafesi (m) } \\
\hline 1.000 .000 & 0,59 & 1,12 & 2,73 & 5,4 & 10,75 \\
2.500 .000 & 0,26 & 0,49 & 1,20 & 2,37 & 4,72 \\
5.000 .000 & 0,15 & 0,28 & 0,69 & 1,36 & 2,71 \\
10.000 .000 & 0,09 & 0,18 & 0,44 & 0,87 & 1,73 \\
\hline
\end{tabular}

Tablo 6'da 18 derece için değișen kapasite ve nakliye mesafesinde öngörülen ton cevher başına taşıma maliyetleri verilmektedir.

Tablo 6. 18 derece eğimli bant nakliye sisteminde tașıma maliyetleri (TL/ton)

\begin{tabular}{cccccc}
\hline & \multicolumn{5}{c}{ Taşıma mesafesi (m) } \\
$\begin{array}{c}\text { Kapasite } \\
\text { ton/yll }\end{array}$ & $\mathbf{5 0 0}$ & $\mathbf{1 0 0 0}$ & $\mathbf{2 5 0 0}$ & $\mathbf{5 0 0 0}$ & $\mathbf{1 0 0 0 0}$ \\
\hline 1.000 .000 & 0,67 & 1,28 & 3,13 & 6,21 & 12,37 \\
2.500 .000 & 0,33 & 0,63 & 1,54 & 3,07 & 6,11 \\
5.000 .000 & 0,21 & 0,41 & 1,01 & 2,02 & 4,04 \\
10.000 .000 & 0,16 & 0,31 & 0,75 & 1,50 & 3,00 \\
\hline
\end{tabular}

Yatay (0 derece) ve 18 derece eğimli bant konveyör hattı için kapasite ve nakliye mesafesine bağlı taşıma maliyetlerindeki değişim sırasıyla Şekil 3 ve 4'de görülmektedir.

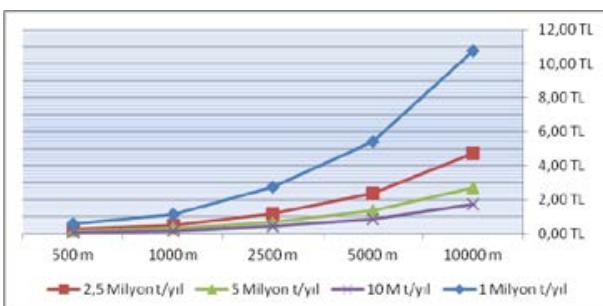

Şekil 3. Kapasite ve nakliye mesafesine bağlı değişen birim taşıma maliyetleri (Yatay eğim)

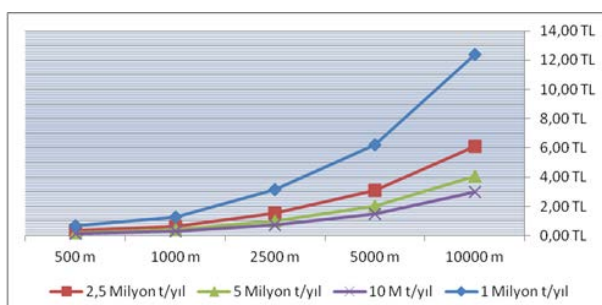

Şekil 4. Kapasite ve nakliye mesafesine bağlı değişen birim taşıma maliyetleri (18 derece eğim)

Açık işletmelerde bantlı konveyör nakliye planlamasında amaç, en ideal mesafe ve eğimde konveyör hattının kurulmasıdır. Çünkü, artan eğim ve mesafe yatırım ve amortismanlarını yükseltmektedir. Günümüzde akaryakıt fiyatları dikkate alındığında, bant konveyör nakliyesi ile ideal olan yerlerde maksimum 18 dereceye herhangi bir mesafe sinırlaması olmaksızın ekonomik nakliye sağlanabilir.

\section{Tartışma ve Sonuç}

Maden işletmeleri için yüksek kapasiteli ve mesafe sınırlaması olmaksızın ideal eğimli arazi ve koşullarda da bant nakliyesinin ekonomik çözümler üretebileceği öngörülmektedir. $\mathrm{Bu}$ nedenle, bant konveyör sistemi daha esnek kapasite ve koşullara uyum sağlama avantajı sağladığından ve ayrıca kapasite artırımına gidilerek işletme ekonomisinde daha rekabetçi değerler sağladığı için maden işletmelerinde uygulanmasının rasyonel ve ekonomik olacağı öngörülmektedir. Ancak çalışmaların daha 
T. Mallı ve A. Gonen / Açık İşletmelerde Bantlı Konveyör Nakliye Sisteminin Değișen Kapasite ve Taşıma Mesafesine Bağlı Ekonomik Analizi

detaylandırılarak değerlendirilmesi ve uygulamalarla desteklenmesi de kaçınılmazdır.

Buna yönelik olarak geleneksel kamyon nakliyesi yerine, sürekli olarak çalışan konveyör bantları ile maden ve malzemelerin taşınması alternatifine odaklanılmaktadır. Bant konveyör uygulamaları enerji tüketimini ve sera gazlarının emisyonlarını azaltacak olup çoğu durumda maliyetleri düşürecektir.

\section{Teșekkür}

Yazarlar, teknik açıdan yardımlarını esirmeyen Labris Madencilik Ltd. Şti'ne teşekkürü bir borç bilir.

\section{Kaynakça}

[1] Gamache, M., Alarie, S. 2002. Overview of Solution Strategies Used in Truck Dispatching Systems for Open Pit Mines: International Journal of Surface Mining, Reclamation and Environment, Cilt. 16, s. 59-76. DOI: 10.1076/ijsm.16.1.59.3408

[2] Verma, D., Kainthola, A., Thareja, R. ve Singh, T. N., 2013. Stability Analysis of an Open Cut Slope in Wardha Valley Coal Field: Journal Geological Society of India, Cilt 17, s. 804-812. DOI: $10.1007 / \mathrm{s} 12594-$ 013-0105-8

[3] Çebi, Y., Köse, H., Yalçın, E. 1994. A Computer Program for the Selection of Open-Pit Mining Equipment and Economical Evaluation of Open-Pit Mining Methods. Proceedings of the Third International Symposium on Mine Planning and Equipment Selection, İstanbul, 417-421.

[4] Lizotte, Y. 1988. Economic and Technical Relations Between OpenPit Design and Equipment Selection. Mine Planning and Equipment Selection, Rotterdam, 3-13.
[5] Şimsir, F., Tatar, Ç., Özfirat, M. K. 2013. Madenlerde nakliyat. Dokuz Eylül Üniversitesi, Mühendislik Fakültesi Yayınları No: 256, İzmir.

[6] Mallı, T. 2006. Küresel Konumlama Sisteminin (GPS) Madencilikte Kullanım Olanaklarının Araştırılması, Dokuz Eylül Üniversitesi, Fen Bilimleri Enstitüsü, Yüksek Lisans Tezi, İzmir.

[7] Braun, T., Hennig A., Lottermoser B. G. 2017.The need for sustainable technology diffusion in mining: Achieving the use of belt conveyor systems in the German hard-rock quarrying industry: Journal of Sustainable Mining, In Press. DOI: 10.1016/j.jsm.2017.06.003

[8] Demirsoy, M. 1984. Transport Tekniği (İletim Makinaları) Cilt I. . Dokuz Eylül Üniversitesi, Mühendislik-Mimarlık Fakültesi Yayınları, İzmir.

[9] Walker, S.C. 1988. Mine Winding and Transport. Elsevier Science Publishers B.V., USA, 545 s.

[10] Yegülalp, T. 2005. Bant Taşımacılı̆̆ı. ss 473-516. Eskikaya, Ş., Karpuz, C., Hindistan, M.A., Tamzok, N., ed. 2005. Maden Mühendisliği Açı Ocak İşletmeciliği El Kitabı, TMMOB Maden Mühendisleri Odası, Ankara.

[11] Zamorano, S. 2011. Surface Ore Movement, Storage, and Recovery Systems, Society Mining Engineering Handbook, Darling, P., (Ed.), Third Edition, USA, s 977987.

[12] Karpuz, C. 2005. Açık Ocak Taşıma Yolu Tasarımı. ss 431-451. Eskikaya, Ş., Karpuz, C., Hindistan, M.A., Tamzok, N., ed. 2005. Maden Mühendisliği Açı Ocak İşletmeciliği El Kitabı, TMMOB Maden Mühendisleri Odası, Ankara.

[13] Özfirat, M.K. 2015. Bantlı Konveyörler. Maden Ocak 
T. Mallı ve A. Gonen / Açık İşletmelerde Bantlı Konveyör Nakliye Sisteminin Değișen Kapasite ve Taşıma Mesafesine Bağlı Ekonomik Analizi

Teknolojileri, Sayı 26, s. 30-32, Apa

Yayıncılık, İstanbul.

[14] Köse, H., Yalçın, E., Şimşir, F., Konak, G., Onargan, T., Kizıl, M.S. 2009. Açık İşletme Tekniği. Dokuz Eylül Üniversitesi, Mühendislik Fakültesi Yayınları, İzmir.

[15] Saltoğlu, S. 2005. Kamyon Taşımacılı̆̆g. ss 453-463. Eskikaya, Ş., Karpuz, C., Hindistan, M.A., Tamzok, N., ed. 2005. Maden Mühendisliği Açlk Ocak İşletmeciliği El Kitabı, TMMOB Maden Mühendisleri Odası, Ankara.

[16] Labris Madencilik Ltd. Şti. www.labris.com.tr (Erişim Tarihi: 21.06.2017). 